\title{
The Evolution of General Internal Medicine (GIM) in Canada: International Implications
}

\author{
Sharon E. Card, MD, MSC, FRCPCl, Heather D. Clark, MD, MSC, FRCPC ${ }^{2}$, \\ Michelle Elizov, MD, MHPE, FRCPC ${ }^{3}$, and Narmin Kassam, MD, MHPE, FRCPC ${ }^{4}$ \\ 'Division of General Internal Medicine, University of Saskatchewan, Department of Internal Medicine, Royal University Hospital, Saskatoon, SK, Canada; \\ ${ }^{2}$ Department of Medicine, University of Ottawa, Ottawa, ON, Canada; ${ }^{3}$ Department of Medicine, McGill University, Montréal, QC, Canada; \\ ${ }^{4}$ Department of Medicine, University of Alberta, Edmonton, AB, Canada.
}

General internal medicine (GIM), like other generalist specialties, has struggled to maintain its identity in the face of mounting sub-specialization over the past few decades. In Canada, the path to licensure for general internists has been through the completion of an extra year of training after three core years of internal medicine. Until very recently, the Royal College of Physicians and Surgeons of Canada (RCPSC) did not recognize GIM as a distinct entity. In response to a societal need to train generalist practitioners who could care for complex patients in an increasingly complex health care setting, the majority of universities across Canada voluntarily developed structured GIM training programs independent of RCPSC recognition. However, interest amongst trainees in GIM was declining, and the GIM workforce in Canada, like that in many other countries, was in danger of serious shortfalls. After much deliberation and consultation, in 2010, the RCPSC recognized GIM as a distinct subspecialty of internal medicine. Since this time, despite the challenges in the educational implementation of GIM as a distinct discipline, there has been a resurgence of interest in this field of medicine. This paper outlines the journey of the Canadian GIM to educational implementation as a distinct discipline, the impact on the discipline, and the implications for the international GIM community.

KEY WORDS: Canada; General internal medicine; Education.

J Gen Intern Med 32(5):576-81

DOI: $10.1007 / \mathrm{s} 11606-016-3891-\mathrm{z}$

(c) Society of General Internal Medicine 2016

G eneral internal medicine (GIM) has struggled to define and advocate for the role of the generalist specialist physician in Canada. ${ }^{1-12}$ The Royal College of Physicians and Surgeons of Canada (RCPSC) was established in 1929, offering only two specialty qualifications: general medicine and general surgery. ${ }^{13}$ This was followed by an expansion of

Received May 2, 2016

Revised August 18, 2016

Accepted September 26, 2016

Published online October 24, 2016 sub-specialization - paradoxically, at the same time as a universal call for increased emphasis on generalism. ${ }^{13,14}$ With a societal need for generalists and a predicted significant shortage of GIM graduates, ${ }^{3}$ the inability to attract trainees to the discipline raised concerns that GIM was a dying and unsustainable discipline. ${ }^{1,3,8,11,15,16}$ This concern about the viability of GIM and the struggle to define the discipline educationally and in scope of practice was reported simultaneously in multiple jurisdictions. ${ }^{17-33}$

General internal medicine has evolved in terms of its operationalization across the world (primary care vs. consultant, ambulatory vs. inpatient), but the values inherent in GIM remain the same. ${ }^{34}$ In Canada, as we have defined and implemented GIM within the educational structure of the national accrediting body (RCPSC), we have been able to standardize educational outcomes with an enhanced ability to describe and advocate for the role of the generalist specialist within the health care system.

\section{GIM PRIOR TO RECOGNITION BY THE RCPSC}

The Canadian path to licensure is described in Figure 1. Prior to 2010, those who effectively became general internists completed an undefined final year of internal medicine training to achieve licensure. The program administration and direction resided with those of the first 3 years of internal medicine, and were not required to be a general internist. The fourth year of internal medicine training was unstructured, with vague objectives and rotation requirements. The vast majority of internal medicine residents used this final year of training as the first year of further accredited subspecialty training, leading to many concerns that the GIM workforce was unsustainable. ${ }^{3}$

Despite the lack of RCPSC recognition and the pull for residents into perceived more lucrative, procedural-based, high-status subspecialty areas, the discipline of GIM matured educationally because of the perceived need and strong advocacy by GIM educators. Prior to and independent of recognition by the RCPSC, the majority of Canadian medical schools voluntarily created GIM programs with independent administrative structures and 


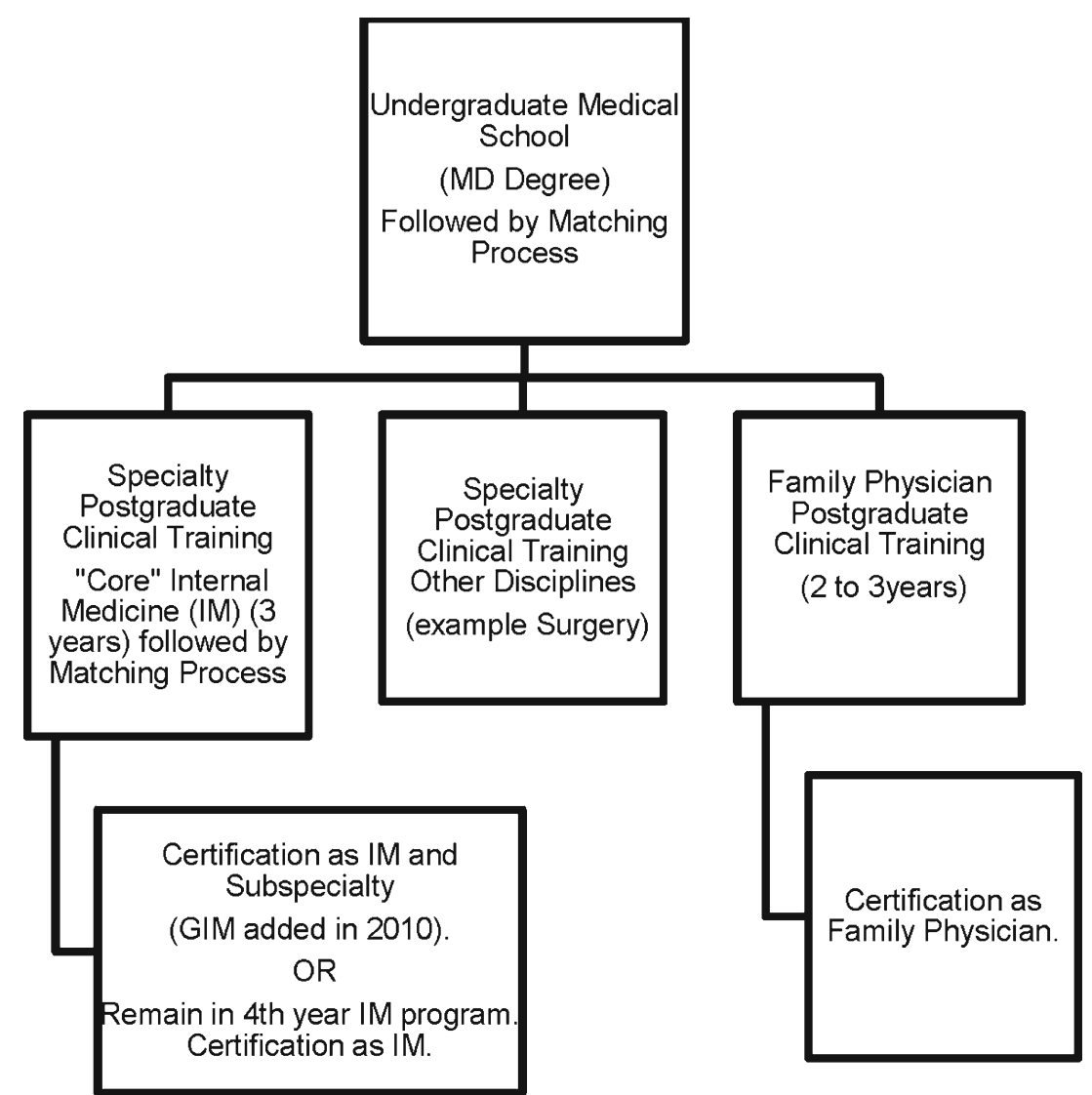

Fig. 1 Canadian path to licensure. All Canadian education is offered by universities. The national college for all specialty postgraduate training is the Royal College of Physicians and Surgeons of Canada (RCPSC). The national college for family physicians is the College of Family Physicians of Canada (CFPC).

objectives unique to the practice of GIM. More than $75 \%$ of those who ultimately practiced GIM at this time sought and completed additional training in order to meet the needs of the society in which they would practice. ${ }^{35} \mathrm{~A}$ number of universities formally supported the additional fifth year of training for GIM trainees to gain sufficient generalist expertise, despite the lack of RCPSC recognition. Even with these voluntary changes, however, the growth of GIM educationally was hampered by the lack of RCPSC recognition, which precluded national accreditation standards to leverage standardization, change and resources for GIM training dedicated to outcomes based on the needs of patients and society.

\section{THE JOURNEY TO RECOGNITION}

Thanks to the dedication of many practicing general internists across Canada, there have been several submissions to the RCPSC over the last 25 years advocating for recognition of GIM as a distinct discipline via the RCPSC submission process (http://www.royalcollege.ca/portal/ page/portal/rc/credentials/discipline recognition/committee on specialties). With RCPSC recognition of a discipline, significant resources are placed into standards via a specialty committee, which allows educators and practicing physicians within the discipline to create objectives, specialty training requirements, and accreditation standards. One of the hurdles was determining where a generalist specialty best fit within the educational structure. The RCPSC defines a specialty as "an area of medicine with a broad-based body of knowledge that is relevant in both community and tertiary settings and is a foundation for additional competencies." A subspecialty is defined "as an area of medicine with a more focused or advanced scope that builds upon the broad-based body of knowledge defined in a parent specialty." ${ }^{36}$ A specialty field is entered directly from medical school, whereas a subspecialty is entered after specialty training, in this case after 3 years of initial specialty training in internal medicine.

\section{SPECIALTY OR SUBSPECIALTY?}

GIM needed to articulate whether it was an area of more focused versus foundational skills with respect to the above-referenced educational definitions by the RCPSC. A review of the scope of practice of GIM in other jurisdictions (Table 2) revealed many similarities with Canadian GIM as specifically articulated in educational outcomes, but the specialty/subspecialty terminology was not used consistently. Discriminating between a specialty 
Table 1 Key Features of Current GIM Training Programs ${ }^{37}$ from RCPSC GIM Objectives of Training

\begin{tabular}{|c|c|}
\hline $\begin{array}{l}\text { THE GIM GRADUATE } \\
\text { WILL: }\end{array}$ & THE GIM GRADUATE WILL: \\
\hline $\begin{array}{l}\text { Be able to manage in the acute } \\
\text { and ambulatory setting: } \\
\text { - Common and emergency } \\
\text { internal medicine conditions } \\
\text { - Internal medicine conditions } \\
\text { before, during and after } \\
\text { pregnancy } \\
\text { - Multisystem disease } \\
\text { - Perioperative care } \\
\text { - Risk reduction }\end{array}$ & $\begin{array}{l}\text { Develop a practice that: } \\
\text { - Is adapted to societal needs } \\
\text { - Maintains generalist principles but } \\
\text { differentiates to the needs of the } \\
\text { community } \\
\text { - Is able to adapt over time } \\
\text { - Respects limits } \\
\text { - Incorporates effective inter- and } \\
\text { intra-professional collaboration, } \\
\text { including excellence in transitions } \\
\text { in care }\end{array}$ \\
\hline $\begin{array}{l}\text { Be able to perform: } \\
\text { - Procedures needed in their } \\
\text { practice }\end{array}$ & $\begin{array}{l}\text { Influence population health } \\
\text { outcomes through: } \\
\text { - Patient safety initiatives } \\
\text { - Preventive care } \\
\text { - Health care delivery initiatives } \\
\text { - Advocacy for vulnerable } \\
\text { populations } \\
\text { - Education (patients, students } \\
\text { and/or colleagues) }\end{array}$ \\
\hline
\end{tabular}

and subspecialty was difficult, for two reasons: (1) the perceived infinite variety of possible scopes of practice, and (2) the variation in functional operational models of GIM within Canada. Considerable emphasis was thus placed on defining the central core of the discipline - the elements of practice common to all general internists at their entry into practice. The current objectives of training and specialty training requirements (Box 1$)^{37}$ were developed through a rigorous process of input and feedback, with a particular focus on input from those who were currently practicing as a full-scope GIM. ${ }^{38,39}$ The objectives were developed over many iterations, requiring a focus on the precise language and terms that would capture the essence while still enabling the whole of GIM to be understood by multiple stakeholders, including the RCPSC, the public, licensing bodies and provincial governments. The objectives demonstrate commonality of scope of practice for all general internists, but recognition that GIM is operationalized differently in different communities and regions in Canada (Table 1). GIM is now a 2-year subspecialty following 3 years of "core" internal medicine training which is common to all subspecialties.
Box One - Definition of $\mathrm{GIM}^{37}$ from Canadian RCPSC Objectives of Training

General Internal Medicine is a subspecialty of Internal Medicine which embraces the values of generalism, is aligned with population needs, and promotes the practitioner's ability to adapt their practice profile when population needs change.

General internists are prepared to diagnose and manage patients with common and emergency internal medicine conditions, and are able to do so when the individual has multiple conditions and with limited access to other subspecialists. General internists provide comprehensive care of the adult patient in an integrated fashion as opposed to an organ-centred or disease-centred approach. They are prepared to maintain stability of patients with multisystem disorders over the long-term or during physiological stresses such as during pregnancy or the peri-operative period.

General Internists advocate for their individual patients as well as for all patients within complex health care delivery systems, by aiming to optimize and not maximize care, including prevention of other conditions. General Internists recognize that the practice of medicine is tightly linked to the art and science of health care delivery and, by virtue of their pivotal role, are uniquely placed to engage in quality improvement, patient safety, and health care system initiatives.

\section{IMPLEMENTATION OF GIM AS A SUBSPECIALTY: CHALLENGES AND REWARDS}

Challenges in achieving acceptance of GIM as a distinct subspecialty were encountered. The RCPSC has a policy of not "grand-parenting" certification until application for and subsequent successful completion of the same examination as all trainees must complete. This included those in practice that championed GIM as a distinct entity and who would not be able to present themselves as "GIM" according to the RCPSC definition. While disappointing to the many practicing GIM physicians that championed and lobbied for recognition, the rationale for this is to assure the public that titles are being accorded appropriately. Therefore, a PER-sub (Practice Eligibility Route for subspecialists) process was developed for assessing the scope of practice to allow practicing general internists access to the examination. ${ }^{40}$ Developing an examination that adequately tests and represents this diverse discipline has been a difficult task, but one that was achievable. ${ }^{41}$

Table 2 Common Features and Challenges of GIM Worldwide W4,37,52-54 $^{3}$

\begin{tabular}{ll}
\hline \hline FEATURES & CHALLENGES \\
\hline $\begin{array}{l}\text { Patient-centered, not organ-centered-comprehensive, evidence-based, } \\
\text { collaborative, coordinated patient care } \\
\begin{array}{l}\text { Provides integrated approach and management across multiple disorders in one } \\
\text { person }\end{array}\end{array}$ & $\begin{array}{l}\text { Insufficient graduates to meet societal needs } \\
\text { Articulating to funders and policymakers the importance and unique } \\
\text { cducated in breadth of disorders but depth in common presentations } \\
\text { Ensuring generalist core of education while at the same time adapting } \\
\text { to future context }\end{array}$ \\
$\begin{array}{l}\text { Adapts to health care system needs } \\
\text { Influences the health care system-innovation in health care delivery } \\
\text { Cost-effective use of health care resources }\end{array}$ & \\
\hline
\end{tabular}


There was concern that GIM becoming a subspecialty would cause residents to lose interest in GIM due to increased length of training, further weakening the GIM workforce. Concern was raised by other medicine subspecialists of the potential for losing dual certification in internal medicine and their specific subspecialty. ${ }^{2,12}$ For these reasons, one of the negotiated points during the journey was to retain the ability for residents to continue to pursue a fourth year of training allowing RCPSC certification as an internist but not as a general internist. Concerns then arose that continuing to allow a four-year certification option in internal medicine would discourage applications in the GIM subspecialty because of the need for extra training. However, since the opportunity to apply to the new GIM subspecialty training programs has become available, there has been unprecedented demand, with a doubling of first-choice applications to GIM. ${ }^{42}$ GIM is now the most popular choice among all internal medicine subspecialty applicants. ${ }^{42}$ Demand currently far exceeds supply.

\section{IMPLEMENTATION OF GIM AS A SUBSPECIALTY: GENERALIST-SUBSPECIALIST BALANCE?}

As the discipline matures, one of the major ongoing discussion points is striking the right balance between generalist skills common to all graduates and ensuring that individual graduates have the skills they need to adapt to their individual practice contexts. ${ }^{43,44}$ Training to manage complex, multisystem, acute or chronic illnesses that interact with one another either in the ambulatory or acute care setting or at times of exacerbation or physiological stressors such as surgery or pregnancy is articulated clearly for all residents in 13 mandatory blocks of training (Table 1). To allow Canadian general internists to practice within multiple contexts, this broad generalist foundation is supplemented with flexibility in 11 blocks of training such that each individual trainee can tailor their training to their future context (Fig. 2). Graduates are being trained to be particularly effective at continuously adapting to the changing health care needs of patients and of their communities. ${ }^{45,46}$ A graduate with a particular procedural skill may practice as a consultant to family physicians in a remote part of Canada, where that skill is needed for that community. Alternatively, a graduate with a research interest in health systems may practice primarily in a large urban hospital. Ironically, this asset to society has been one of the challenges of educational implementation, as the balance between the flexibility required for addressing specific community needs and the standardization for individual residents is still being defined. As competency-based medical education is being embraced in Canada, ${ }^{47}$ this balance is a key discussion point for GIM.

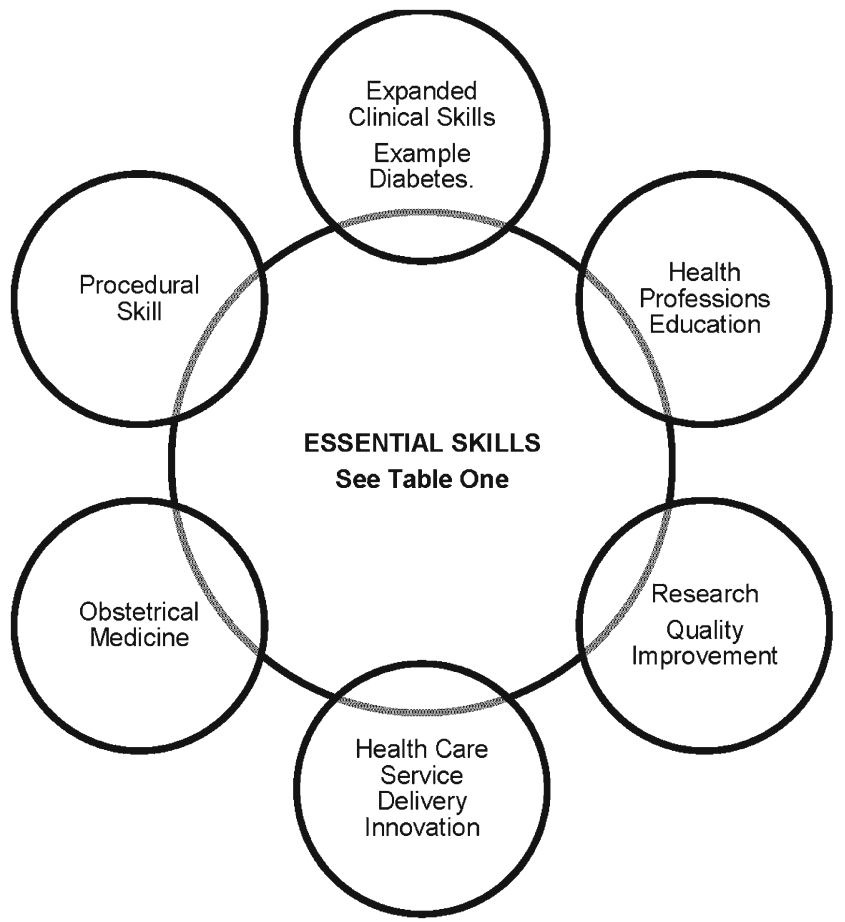

Fig. 2 Educational content of GIM training leading to variability in scope of practice adapted to future training locale. The center indicates those skills all residents attain, while the outside areas are examples of areas of concentrated education for individual graduates, depending on their future practice location.

\section{LESSONS LEARNED DURING IMPLEMENTATION OF THE DISCIPLINE}

The biggest challenge for the Canadian GIM community was coming together around a nationally accepted and articulated definition of a general internist and of the scope of practice of GIM. This related to both whether the discipline was a specialty (foundational) or subspecialty (focused and advanced), and the balance between generalist skills and individual skills targeted to a particular community. As Ghali noted in his paper on the internationalization of GIM, "Borrowing metaphorically from the field of biostatistics, it seems that the existing 'within-country variance' in GIM profiles is not all that different from the 'between-country variance." 34 Within Canada, GIM has a wide scope of practice - hospital-based, consultant-based and academic, among many others. Differences in scope of practice often (although not always) fall along rural versus urban lines, leading to tensions between these locations. To gain this common understanding, input was sought from those practicing GIM in many locations, and was synthesized through the Canadian Society of Internal Medicine meetings and surveys, ${ }^{38,39,45,46}$ this occurred in parallel with ongoing quality GIM training, despite the lack of recognition. The graduates of the initial unaccredited programs themselves recognized that they were providing a valuable and unique service to the populations they served, and so became increasingly united in their bid for recognition. As we operationalized the discipline, stakeholder engagement was made difficult by the lack of a common identifying 
national "home." Many practicing general internists did not identify with the national generalist specialty society, but often identified with a focused clinical area or regional society. There was a need to deliberately reach out to practicing general internists via regional representatives, division heads and program directors, in addition to contact with the national specialty society.

It was important to explicitly acknowledge GIM's vast potential scope of practice, with prior conversations around differences being counterproductive. The existence of unaccredited programs and the educational leaders who advocated for and implemented them were instrumental in identifying the commonalities and coming to a unifying vision.

\section{CONCLUSIONS}

GIM in Canada has been expanding rapidly since it was defined as a distinct discipline by the RCPSC. Concentrating on educational outcomes based on societal needs versus geographical differences in roles has been a key driver in revitalizing the discipline in Canada. Despite different nomenclature and operational models among countries, there are many more similarities and common challenges for GIM (Table 2). Therefore, as Ghali suggested, ${ }^{34}$ the time is right for the development of a strong international GIM community. ${ }^{34} \mathrm{We}$ suggest that sharing successes and challenges in GIM education worldwide will further promote revitalization of GIM through an international community striving for optimal education in teamwork, chronic disease, patient-centered care and innovation in the health care system. ${ }^{34}$ Expanding to include an international network of GIM academics ${ }^{48-50}$ and researchers will optimize the ability of GIM to further expand. We believe that initiatives such as this call for international papers by JGIM will assist GIM in developing an international perspective in clinical practice and research. ${ }^{51}$ We would add an international perspective in education to that mix.

Corresponding Author: Sharon E. Card, MD, MSc, FRCPC; Division of General Internal Medicine, University of Saskatchewan, Department of Internal MedicineRoyal University Hospital, 103 Hospital Drive, Saskatoon, SK, Canada (e-mail: sharon.card@usask.ca).

\section{Compliance with Ethical Standards:}

Funders: None.

Prior Presentations: Part of this article was presented at the Canadian Conference on Medical Education, 2014.

Conflict of Interest: The authors declare that they do not have a conflict of interest.

\section{REFERENCES}

1. Baillie $\mathbf{H}$, Kenyon $\mathbf{M}$. General internal medicine: A core specialty in jeopardy. BC Med J. 2005;47(7):377-8.
2. Canadian Association of Interns and Residents. CAIR Position Statement on the Proposal to Recognize General Internal Medicine as a New Subspecialty. 2010.

3. Canadian Society of Internal Medicine. Care-Fully: Defining a Plan for General Internal Medicine in Canada. 2005.

4. Cook DJ, Griffith LE, Sackett DL. Importance of and satisfaction with work and professional interpersonal issues: A survey of physicians practicing general internal medicine in Ontario. Can Med Assoc J. 1995;153(6):755-64.

5. Goldsand G, Thurber AD. The Overlapping Roles of Primary Care Physicians, General Specialists and Subspecialists - The Canadian Perspective. Presented at 7th International Medical Workforce Conference Oxford, United Kingdom. 2003.

6. Hollenberg $\mathbf{C H}$, Langley GR. The Canadian general internist: education and future role. CMA J. 1978;118:397-400.

7. McConnon JK, Shah CP. Patterns of practice in internal medicine in Ontario. CMA J. 1977;116(11):1269-73.

8. Phillipson EA. Chair's Column. Is general internal medicine in the twilight of its existence? Medinews. The Newsletter of the Department of Medicine University of Toronto. 1994; 5(4): 1-4.

9. Robinson A. Forging a new subspecialty: general internal medicine. Can Med Assoc J. 1994;150(12):1995-8.

10. Sinclair GE, Morton C. The Canadian general internist. CMA J. 1978;119(2): 118.

11. Sullivan P. Internists worried as concern about general medicine's future spreads. CMAJ. 2003;168(8): 1032.

12. Vogel L. Internal bickering over internal subspecialty. CMAJ. 2010;182(12): 1287-8.

13. Royal College of Physicians and Surgeons of Canada website - Our History. Available at: http://www.royalcollege.ca/rcsite/about/our-history-e. Accessed September 8th 2016.

14. Royal College of Physicians and Surgeons of Canada website - Report of the Generalism and Generalist Task Force. Available at: http://www.royalcollege. ca/rcsite/education-strategy-accreditation/innovations-development/initiatives/generalism-medical-education-e Accessed September 8th 2016.

15. Daniels VJ, Kassam N. Impact of personal goals on the internal medicine R4 subspecialty match: A $\mathrm{O}$ methodology study. BMC Med Educ. 2013;13(171): $1-9$.

16. Horn L, Tzanetos K, Thorpe K, Straus SE. Factors associated with the subspecialty choices of internal medicine residents in Canada. BMC Med Educ. 2008;8(37): 1-8.

17. Bauer W, Schumm-Draeger PM, Koebberling $\mathbf{J}$, et al. Political issues in internal medicine in Europe. A position paper. Eur $\mathrm{J}$ Intern Med. 2005; 16(3):214-7.

18. Chee YC. 1st College of Physicians Lecture: The Role of Internal Medicine as a Specialty in the Era of Subspecialization. Ann Acad Med Singapore. 2004;33:725-32.

19. Cranston M, Semple C, Duckitt R, et al. The practice of internal medicine in Europe: organisation, clinical conditions and procedures. Eur $\mathrm{J}$ Intern Med. 2013;24(7):627-32.

20. Gunn J, Naccarella L, Palmer V, Kokanovic R, Pope C, Lathlean J. What is the Place of Generalism in the 2020 Primary Health Care Team? Canberra: Australian Primary Health Care Research Institute.

21. Internal Medicine Society of Australia and New Zealand and The Royal Australasian College of Physicians. Restoring the balance. An action plan for ensuring the equitable delivery of consultant services in general medicine in Australia and New Zealand 2005 - 2008. September 2005.

22. Internal Medicine Society of Australia and New Zealand. General Medicine in Australia and New Zealand. The Way Forward. 2000. https://www.imsanz.org.au/resources/general-medicine-in-australiaand-new-zealand-the-way-forward Accessed September 8th 2016.

23. Jackson A, Baron RB, Jaeger J, Liebow M, Plews-Ogan M, Schwartz MD, Society of General Internal Medicine Health Policy Committee. Addressing the nation's physician workforce needs: The Society of General Internal Medicine (SGIM) recommendations on graduate medical education reform. J Gen Intern Med. 2014;29(11):1546-51.

24. Julian K, Riegels NS, Baron RB. Perspective: Creating the next generation of general internists: a call for medical education reform. Acad Med. 2011;86(11):1443-7.

25. Kravitz RL, Feldman MD. General internal medicine as an engine of innovation. J Gen Intern Med. 2013;28(6):749-50.

26. Larson EB, SGIM Task Force on the Domain of General Internal Medicine. 1Health care system chaos should spur innovation: summary of a report of the Society of General Internal Medicine Task Force on the Domain of General Internal Medicine. Ann Intern Med. 2004;140(8):639-43. 
27. Larson EB, Fihn SD, Kirk LM, et al. The future of general internal medicine. Report and recommendations from the Society of General Internal Medicine (SGIM) Task Force on the Domain of General Internal Medicine. J Gen Intern Med. 2004;19(1):69-77.

28. Larson et al. SGIM Task Force. The Future of General Internal Medicine. Task Force on the Domain of General Internal Medicine. Society of General Internal Medicine. 2003. http://www.sgim.org/futureofGIMreport.pdf. http://impak.sgim.org/userfiles/file/futureofGIM.pdf Accessed September 8th 2016.

29. Monti M, Gachoud D. Nouveau programme de formation en médicine interne général : implications pour les médecins de premier recours. Rev Med Suisse. 2010;6(269):2087-92.

30. Moore A, Newberry N, Goddard AF. Consultant perception of general internal medicine: a survey of consultant physicians. Clin Med (Lond). 2015;15(6):511-9.

31. Parenti CM. The kaleidoscope of general internist careers: a challenge for internal medicine training. Acad Med. 1995;70(4):282-5.

32. Waeber G, Cornuz J, Aujesky D, Gaspoz JM, Perrier A. Défis et opportunités. Iles à la création d'une société unique de spécialistes en médecine interne générale en 2015. Rev Med Suisse. 2014;10(414): 149-52.

33. West C, Dupras DM. General medicine vs subspecialty career plans among internal medicine residents. JAMA. 2012;308(21):2241-7.

34. Ghali WA, Greenberg PB, Mejia R, Otaki J, Comuz J. International perspectives on general internal medicine and the case for "globalization" of a discipline. J Gen Intern Med. 2006;21(2):197-200.

35. McAlister F, O'Brien B. General Internal Medicine Subspecialty Application Briefing Note. 2010.

36. Royal College website - Definition of Specialty and Subspecialty. Available at: http://www.royalcollege.ca/rcsite/education-strategy-accreditation/ innovations-development/categories-discipline-recognition-e Accessed September 8th 2016

37. Royal College website - Subspecialty of General Internal Medicine Available at: http://www.royalcollege.ca/rcsite/credentials-exams-e Accessed September 8th 2016.

38. Card SE, Snell L, O'Brien B. Are Canadian General Internal Medicine training program graduates well prepared for their future careers? BMC Med Educ. 2006;6(56):1-9.

39. Card SE, PausJenssen AM, Ottenbreit RC. Determining specific competencies for General Internal Medicine residents (PGY 4 and PGY 5). What are they are programs currently teaching them? A survey of practicing Canadian General Internists. BMC Res Notes. 2011;4(480):1-6.

40. Royal College website - Credentials. PER Sub Route Documents. Available at: http://www.royalcollege.ca/rcsite/credentials-exams/exam-eligibility/ assessment-imgs/practice-eligibility-route-per-sub-subspecialists-e Accessed September 8th 2016.

41. Pugh D, Govig B, Gibson N, Cole G. The General Internal Medicine Certification Examination: Does it Measure What it Should? CJGIM. 2016;11(1):30-3.

42. CARMs website - Medicine Subspecialty Match - Data and Reports. Available at: http://www.carms.ca/en/data-and-reports/msm/ Accessed September 8th 2016.

43. Jamieson J, Towle A. Future Health Care Trends: Impact on Postgraduate Medical education. Members of the FMEC PG consortium; 2011.

44. Anderson L, Ward HA, Card SE. Linking General Internal Medicine Residency Training to Human Resource Needs and Roles in a Changing Health Landscape. Univ Sask Undergrad Res J. 2015;1(2):01-7.

45. Card SE, Ward H, Anderson L. Preparing General Internal Medicine (GIM) Residents for the Real World - Can We Predict GIM Human Resource Needs in a Changing Health Landscape? Poster Presentation at Society of General Internal Medicine 2015 April Toronto. Published as abstract in JGIM S233234. May 2015.

46. Card SE, Ward HA, Broberg L. Preparing General Internal Medicine (GIM) Residents for the Future - Aiming to Match Training to Need - A Pilot Study in Saskatchewan. CJGIM. 2016;11(2):26-31.

47. Card SE, Kassam N. The Future is Bright for Competency-based Education in General Internal Medicine. CJGIM. 2016;11(1):25-9.

48. Armstrong K, Keating NL, Landry M, Crotty BH, Phillips RS, Selker HP, Council of the Society of General Internal Medicine. Perspective. Academic general internal medicine: a mission for the future. $\mathrm{J}$ Gen Intern Med. 2013;28(6):845-51.

49. Levinson W, Linzer $\mathbf{M}$. What is an academic general internist? Career options and training pathways. JAMA. 2002;288(16):2045-8.

50. Tanriover MD, Rigby S, van Hulsteijn $\mathbf{L H}$, et al. What is the role of general internists in the tertiary or academic setting? Eur J Intern Med 2015;26(1):9-11.

51. Feldman MD. From the Editor's Desk. International Perspectives on General Internal Medicine. J Gen Intern Med. 2016;31(3):259.

52. IMSANZ Website - What is a General Physician. Available at: https://www. imsanz.org.au/about-us/what-is-a-general-physician Accessed September 8th 2016

53. SGIM Website - What is a General Internist. Available at: http://www.sgim. org/career-center/proudtobegim/proudtobegim Accessed September 8th 2016.

54. European Federation of Internal Medicine Website. Available at: http:// www.efim.org/about/what-internal-medicine Accessed September 8th 2016 